\title{
MEDIAÇÃO DA LEITURA EM BIBLIOTECAS: APROXIMAÇÃO ÀS ESPECIFICIDADES DA LEITURA LITERÁRIA
}

\section{MEDIATION OF READING IN LIBRARIES: APPROXIMATION TO THE SPECIFICITIES OF LITERARY READING}

\author{
https://doi.org/10.20873/uft2179-3948.2020v11n3p57-74
}

\section{Regina Garcia Brito ${ }^{1}$}

\begin{abstract}
Resumo: A partir de uma revisão de literatura, o artigo aborda três diferentes paradigmas culturais de bibliotecas (PERROTTI, 2016, 2017; PERROTTI e PIERUCCINI, 2007, 2014) e sua influência nos modos de ler e de mediar a leitura literária. Trata das funções da literatura, sua relação com formação, conhecimento, experiência, terapia, entre outras (CANDIDO, 2012; OBERG, 2007; YUNES, 2019). Reflete sobre as categorias compartilhamento e escuta para a mediação da leitura literária (PETIT, 2013, 2017; PATTE, 2012; BAJOUR, 2012) e sugere a possibilidade de ressignificação de bibliotecas públicas como espaços que podem contribuir para a formação do leitor literário.
\end{abstract}

Palavras-chave: mediação; bibliotecas; literatura; leitura literária

Abstract: This article explores three different libraries cultural models as proposed by Perrotti $(2016,2017)$ and Perrotti and Pieruccini $(2007,2014)$ and the way each one influences reading and mediation of literary reading. To do so, we refer to the role of literature and how it is related to subject formation, knowledge, therapy, among others (CANDIDO, 2012; OBERG, 2007; YUNES, 2019). We also discuss the sharing and hearing types of literary reading mediation (PETIT, 2013, 2017; PATTE, 2012; BAJOUR, 2012), and suggest the possibility of reframing public libraries as arenas that can contribute to the formation of literary readers.

Keywords: mediation; libraries; literature; literary reading

\section{Introdução}

A Sociedade da Informação é marcada pela velocidade com circulam e se produzem informações, no entanto, nossa capacidade de processá-las, significá-las e delas nos apropriarmos não segue o mesmo ritmo de sua produção e difusão (BOSI, 1995). Além disso, com a cultura digital, aumentou o quadro de descontextualização das informações e do

\footnotetext{
${ }^{1}$ Mestranda no Programa de Pós-Graduação em Ciência da Informação (PPGCI), do Departamento de Informação e Cultura (CDB), da Escola de Comunicações e Artes (ECA), da Universidade de São Paulo (USP) e membro do Grupo de Pesquisa em Educação Cultural (GPEC). Bibliotecária na Unifesp - câmpus zona leste. E-mail: regina.garcia@usp.br
} 
conhecimento, tornando-se cada vez mais necessário desenvolver estratégias, além de dispositivos de mediação cultural, que possibilitem o compartilhamento de conhecimentos e a "ruminação" intelectual (PIERUCCINI, 2004).

Em Considerações sobre tempo e informação, Bosi (1995) afirma que a satisfação dos nossos desejos mais profundos se faz em um clima alheio ao tempo do relógio. Por outro lado, mais do que ter acesso a todas as informações disponibilizadas, é preciso, como diz o autor, saber perguntar: "quem não sabe perguntar, quem não sabe O QUE perguntar, o que fará com a torrente de informações potenciais que as redes eletrônicas lhe podem oferecer?" (BOSI, 1995). Existe um estado mental que gera as boas perguntas e elas precisam ser formuladas antes de consultar os arquivos.

A relação com a literatura insere-se nessa problemática geral que atinge nossas relações com os signos na contemporaneidade. Considerada um objeto social com potencial humanizador (CANDIDO, 2004), a literatura relaciona-se ao conhecimento, ao autoconhecimento, à formação cultural, a processos terapêuticos, entre outros. Enquanto tal, necessita de tempo para fruição ao mobilizar diferentes faculdades do leitor, colocando-o à prova, fazendo-lhe perguntas, provocando inquietações, emoções, afetos.

A leitura literária possui particularidades, diferenciando-se de outras leituras. Segundo o verbete leitura literária, definido por Graça Paulino (2014) para o Glossário Ceale:

\footnotetext{
A leitura se diz literária quando [...] o pacto entre leitor e texto inclui, necessariamente, a dimensão imaginária, em que se destaca a linguagem como foco de atenção, pois através dela se inventam outros mundos, em que nascem seres diversos, com suas ações, pensamentos, emoções.

A linguagem se mostra não apenas um meio de comunicação, mas um objeto de admiração, como espaço da criatividade. Misturada à vida social, a leitura literária merece atenção da comunidade, por constituir uma prática capaz de questionar o mundo já organizado, propondo outras direções de vida e de convivência cultural [...] (PAULINO, 2014)
}

Sendo a obra literária é uma construção artística, o importante não é somente o que o texto diz e sim como diz. As palavras são articuladas pelo autor e isso é o seu primeiro nível humanizador. Código e mensagem não se separam. "A produção literária tira as palavras do nada e as dispõe como todo articulado (...) A organização da palavra comunica-se ao nosso espírito e o leva, primeiro, a se organizar; em seguida a organizar o mundo" (CANDIDO, 2004, p. 177).

Oberg (2007), em estudo sobre a fruição literária, afirma que por seu caráter de gratuidade - no sentido do que não visa fins utilitários -, a literatura tem sido colocada em risco 
face à velocidade e à funcionalização na vida moderna, ou seja, a literatura é afetada pelo tempo acelerado.

Nesse sentido, haveria nas bibliotecas públicas, uma situação diferente da escola, pois, em princípio, a leitura literária não sofreria ali as cobranças ligadas aos programas escolares. Tal condição abriria possibilidades de se propiciar nesses espaços condições de fruição literária, permitindo que cada um pudesse encontrar na leitura algo vinculado às suas próprias questões, pois, como afirma Petit (2017, p. 23), há "apropriações singulares, às vezes até mesmo desviando-se dos textos lidos".

Fruição, entretanto, não se trata de um fenômeno espontâneo e linear. Ao contrário, envolve tanto "processos mentais complexos por parte do sujeito, que englobam desde o raciocínio lógico (associação, dedução, antecipação, inferência), até aspectos afetivos, emocionais, sensoriais, imaginativos, culturais, de memória, entre outros" (OBERG, 2007, p. 47).

Vale lembrar que a biblioteca pública, vista como instância de mediação cultural, é constituída de elementos materiais e imateriais, em relação direta com processos de apropriação das informações por ela disseminadas e mediadas. Tais elementos - como o espaço físico, a organização dos documentos, os recursos informacionais, as práticas educacionais e culturais, entre outros - estão articulados, em geral, sob uma mesma ordem, uma mesma intencionalidade (PIERUCCINI, 2007), que se relacionam com os atos de recepção, facilitando-os ou criando obstáculos.

Por outro lado, as mediações da leitura literária são diferentes das realizadas para um texto científico ou informativo, independentemente da idade do leitor, dadas as especificidades da matéria com que lidam (OBERG, 2007). Para que se efetive a apropriação das obras, sua fruição, a aproximação física ao objeto material pode não ser suficiente (aproximação que pode ser dificultada por regras e ambiente vistos como hostis por leitores pouco experientes), sendo necessárias ações de mediação e o estabelecimento de relações, muitas vezes personalizadas, entre bibliotecários e leitores, criação de vínculos simbólicos e afetivos, em especial com pessoas que não tiveram contato com obras literárias na infância, tendo o mediador o papel de "autorizar, legitimar, um desejo inseguro de ler ou aprender, ou até mesmo revelar esse desejo" (PETIT, 2013, p. 148).

Com base nesse contexto, o presente texto tem por objetivo tratar das especificidades da mediação da leitura literária em bibliotecas. Inicia-se com descrição de três diferentes paradigmas de bibliotecas (PERROTTI, 2016, 2017; PERROTTI e PIERUCCINI, 2007, 2014) 
e suas influências na relação nos modos de ler, destacando o modelo de "mediação cultural", enquanto referencial metodológico importante para a valorização do sujeito leitor. Em seguida, trata das funções da literatura, sua relação com a formação, conhecimento, experiência, terapia, entre outras (CANDIDO, 2012; OBERG, 2007; YUNES, 2019). Por fim, reflete sobre a importância das categorias compartilhamento e escuta para a mediação da leitura literária em bibliotecas (PETIT, 2013, 2017; PATTE, 2012; BAJOUR, 2012), uma mediação a ser planejada de forma criteriosa, à luz de conhecimentos específicos, dado que não se constitui como simples transmissão ou mera permissão de acesso aos bens culturais.

\section{Paradigmas culturais: da conservação e da difusão à mediação cultural}

As bibliotecas públicas foram criadas no Iluminismo com o objetivo de possibilitar a todos o acesso a informações que até aquele momento haviam sido negadas a muitos segmentos da população. No entanto, o projeto difusionista do Iluminismo assentava-se na assimilação de valores e saberes transmitidos por uma elite cultural, sendo inadmissível questionar os paradigmas apresentados, ou seja, a assimilação aqui era compreendida como uma recepção passiva das informações transmitidas, considerando-se cultura apenas aquela das elites, o que era uma forma de "homogeneização cultural, a adoção de um modelo cultural único" (PERROTTI, 2016, p. 20). Esse discurso difusionista, segundo Perrotti, continua orientando práticas até os dias atuais, partindo da "premissa de que a disponibilização de bens culturais gera automaticamente apropriação" (2016, p. 19).

Diferente do difusionista, o paradigma de mediação cultural define-se pela apropriação e protagonismo cultural, que, apesar de estarem vinculados a uma dimensão material e objetiva da vida sociocultural, não se restringem a ela, envolvendo também processos imateriais e subjetivos dinâmicos e complexos. Nesses termos, apropriar-se seria ação afirmativa, invenção e criação (PERROTTI; PIERUCCINI, 2007). Tal ato implica operações que mobilizam tanto forças próprias aos sujeitos como relações ativas com o meio sociocultural e seus dispositivos. Como afirmam Rastelli e Cavalcante (2014, p. 48), “conjectura-se que a mediação cultural comporta elementos como produção e recepção de bens simbólicos (as diversas atividades culturais) e os dispositivos culturais (bibliotecas) como espaços de apropriação".

O termo mediação tem sido usado em várias áreas, como a jurídica, a religiosa, a educacional (PERROTTI; PIERUCCINI, 2014, p. 2). Em nossa área de pesquisa, tem sido visto, em geral, como categoria funcional ou instrumental. No entanto, pode ser equiparado às 
categorias de produção e de recepção, mais que locus, portanto ato técnico ou funcional de exercer intermediação, a mediação cultural é "ação portadora de sentidos próprios que estão em relação com sentidos incrustados tanto nos objetos, como nos sujeitos culturais e seus respectivos contextos" (PERROTTI; PIERUCCINI, 2014, p. 9).

A mediação cultural refere-se a um conjunto de elementos de diferentes ordens (material, relacional, semiológica) que se interpõem e atuam nos processos de significação; inclui "a constituição de acervos, organização dos espaços, frequência na realização das atividades culturais e práticas pedagógicas" (RASTELLI; CAVALCANTE, 2014, p.44). É ato "implícito" ou "explicito", conforme referência anterior, de produção de sentidos. A mediação cultural leva a considerar os elementos que constituem seus processos não como simples ferramentas, mas como signos.

Dada tal compreensão, o conceito de mediação articula-se ao de protagonismo cultural, o qual é definido como:

fenômeno de participação ativa e afirmativa na vida cultural, na condição de produtor e criador de significados e sentidos, seja individualmente ou enquanto membro de um grupo ou uma coletividade (PERROTTI; PIERUCCINI, 2007, p. 56)

Compreendidos como protagonistas, os sujeitos, sob o modelo da mediação cultural, passam a ter papel central na cultura e, em suas relações com os signos, criam, recriam e se recriam, são sujeitos e objetos dos processos dinâmicos em que se acham inseridos, não são meros usuários ou consumidores culturais. Ao ter uma relação viva com o mundo, o protagonista participa ativamente de processos de criação de sentidos para si e para o mundo, exercendo o direito cidadão fundamental de significar e nomear o mundo (PERROTTI, 2017). Assim, essa abordagem abrange também o profissional da mediação, o qual, conforme Gomes (2014, p. 47): “age, constrói e interfere no meio, portanto, é também um protagonista social, e nessa condição se constitui em sujeito da estética, da ética e da produção humanizadora do mundo".

Os mediadores de leitura, nesse sentido, apresentam-se como um "terceiro", articulado com o texto e o leitor; mais que intermediários, são atores de transformação cultural e mobilizam um conjunto diverso de mediações (PERROTTI; PIERUCCINI, 2014). Esse modelo em que se relacionam produtor-mediador-leitor é apresentado por Perrotti e Pieruccini (2014) como modelo triádico que rompe com o modelo diádico de informação e de comunicação produtor-leitor. incluindo, portanto, o mediador como categoria da significação e não como mero "transferidor", canal "neutro", "passador cultural".

Nesse contexto, vale lembrar que 
os dispositivos culturais passam a ser concebidos como instâncias de negociação de signos por sujeitos tomados em sua dimensão de criadores culturais, da mesma forma que os processos de mediação passam a ser entendidos como ato constitutivo dos processos de construção de sentidos e, ele próprio instância produtora de significação (PERROTTI; PIERUCCINI, 2014, p. 19)

A configuração, as formas e dinâmicas assumidas pelos dispositivos são, por conseguinte, parte dos processos de mediação e das relações entre mediadores e mediados. Nesse sentido, apropriar-se dos signos vem a ser mais que o reconhecimento de possíveis sentidos referenciais, pois envolve a apropriação das formas, dos dispositivos, e de saberes e lógicas que lhes conferem sentidos próprios. O conceito de dispositivo contém uma dimensão material e outra simbólica. A sua organização, suas linguagens e interações atuam nos processos de apropriação da informação. Os dispositivos "não apenas expressam como também definem, por meio dos discursos implícitos em sua configuração, modos de relação entre os sujeitos e o universo simbólico [...] que guardam" (PIERUCCINI, 2004, p, 36).

Em síntese, nesse tópico, ao descrever três paradigmas culturais -conservação, difusão e mediação cultural - procuramos expor três concepções de bibliotecas que se distinguem em razão de modelos epistêmicos que decorrem e reforçam não só bibliotecas, mas políticas e práticas culturais e criam cenários culturais distintos e que, no caso que nos interessa diretamente, atuam nos modos de relação dos públicos com a literatura. Enquanto nos dois primeiros modelos, o foco é a preservação ou a circulação do acervo, no modelo de mediação cultural, as relações de dupla mão dos acervos literários com os sujeitos ganham destaque e papel central, não aparecendo nem a cultura letrada como objeto a ser cultuado, nem os leitores, apenas como meros consumidores de signos. Em outras palavras, a prática da leitura, tomada como experiência viva e vivificante, tem na conservação e na difusão das obras categorias instrumentais importantes, mas sua apropriação é a categoria fim (OLIVEIRA, 2009, p. 21).

Apresentaremos a seguir algumas funções da literatura e visões que colocam os leitores como participantes ativos dos significados das obras. Acreditamos que nesse contexto, o leitor é visto também como protagonista e não mero receptor ou consumidor do que é lido.

\section{Algumas funções da literatura e a valorização da subjetividade do leitor}

A literatura relacionada à formação do homem pode se referir à satisfação de uma necessidade universal de fantasia e ficção (função psicológica), colaborando para a formação da personalidade bem como para o conhecimento do mundo e do ser. Todavia, a função educativa da literatura é "muito mais complexa do que pressupõe um ponto de vista estritamente 
pedagógico. A própria ação que exerce nas camadas profundas afasta a noção convencional de uma atividade delimitada e dirigida segundo os requisitos das normas vigentes." (CANDIDO, 2012, p. 84) É preciso lembrar que “ela não corrompe nem edifica, portanto; mas, trazendo livremente em si o que chamamos o bem e o que chamamos o mal, humaniza em sentido profundo, porque faz viver" (CANDIDO, 2012, p. 85). No entanto, é certo que a literatura não é neutra, "a fabulação não está imune ao contágio do ideológico, seja como endosso ou crítica" (YUNES, 2019, p. 35).

Devido a esse potencial educativo e de formação, de tempos em tempos, as obras literárias são alvo de críticas, pois são consideradas possíveis fontes de perversão ou subversão. Seus conteúdos podem ser interpretados como ideológicos e um exemplo disso é a leitura que se fez do livro Meninos sem pátria, de Luiz Puntel, que foi suspenso, em 2018, por um colégio do Rio de Janeiro, acusado de apologia ao comunismo².

As críticas a obras literárias, entretanto, não partem apenas de grupos conservadores da sociedade. Como exemplo, há o caso do livro Peppa, de Silvana Rando, retirado de circulação pela autora, após ser acusado de racismo ${ }^{3}$. Essa “perseguição" mostra, como afirma Compagnon (2009), justamente o seu poder: "a literatura é de oposição: ela tem o poder de contestar a submissão ao poder. Contrapoder, revela toda a extensão de seu poder quando é perseguida" (COMPAGNON, 2009, p. 34).

A literatura tem também um potencial de experiência, como mostra Larrosa (2011), em seu texto sobre experiência e alteridade em educação, , podendo assim ajudar o leitor a dizer o que ainda não sabía , formar ou transformar a linguagem. A experiência é única, singular e difere de pessoa para pessoa. A cada nova leitura, uma nova experiência pode se estabelecer, ou seja, além do "princípio da singularidade", a relação com a literatura segue o "princípio da irrepetibilidade". A obra literária é sempre renovada a cada leitura, "não é um objeto que exista por si só, oferecendo a cada observador em cada época um mesmo aspecto” (JAUSS, 1994, p. 25).

\footnotetext{
${ }^{2} \mathrm{O}$ caso ocorreu no Colégio Santo Agostinho, unidade Leblon, no Rio de Janeiro. O livro mencionado fazia parte da lista de leitura para estudantes do $6^{\circ}$ ano do Ensino Fundamental. Disponível em: <https://lunetas.com.br/livromeninos-sem-patria/>. Acesso em: 19 dez. 2019.

${ }^{3}$ O livro virou alvo de contestação, em 2017, quando a youtuber, empresária de moda e ativista Ana Paula Xongani fez um vídeo no qual apresentava uma resenha com muitas críticas ao livro. Disponível em: <https://g1.globo.com/educacao/noticia/acusacao-de-racismo-faz-autora-tirar-livro-peppa-de-circulacao.ghtml > Acesso em 19 dez. 2019.
} 
Larrosa (2011) relembra as considerações de Walter Benjamin, feitas em seu famoso ensaio Experiência e pobreza de 1933, em que trata da relação entre abundância de estímulos e pobreza de experiências. Larrosa procura mostrar como a avalanche informacional, a obsessão por estar sempre informado, o excesso de opinião, todas substituíveis por outras mais novas, não se convertem em visão crítica da realidade e nem criam conexões significativas, diferentemente do acontece com a leitura de textos literários (LARROSA, 2011).

A leitura de uma obra literária pode ser uma experiência para algumas pessoas e não para outras. Petit (2013) cita exemplos de leituras significativas, imprevistas, e defende que não se estabeleçam listas definitivas de obras mais ou menos adequadas:

\begin{abstract}
quem poderia imaginar que Descartes seria a leitura preferida de uma jovem turca preocupada em escapar de um casamento arranjado, que a biografia de uma atriz surda permitiria a um jovem homossexual assumir sua própria diferença, ou que os sonetos de Shakespeare inspirariam um jovem laosiano, operário de construção, a escrever canções? (PETIT, 2013, p. 184).
\end{abstract}

Importa dizer que a relação da literatura com a humanização não se restringe ao Ensino Fundamental e médio e a instituições culturais. Na Escola Paulista de Medicina, da Universidade Federal de São Paulo (Unifesp), por exemplo, há um grupo, liderado pelos professores Dante Gallian e Rafael Ruiz, preocupado em discutir a importância da formação humana na área da saúde. Com alunos do curso de Medicina, foi criado o denominado Laboratório de Humanidades (LabHum), fundamentado na leitura e discussão de obras literárias. $\mathrm{O}$ grupo surgiu de encontros informais na hora do almoço e hoje mantém aulas na graduação e pós-graduação, abertas a estudantes de outras áreas. A experiência do LabHum ${ }^{4}$ entende esse contato com a literatura como um "efetivo caminho humanizador (...) se fundamenta numa experiência estético-reflexiva e não num processo técnico-cognitivo" (GALLIAN, 2017, p. 51).

Na descrição da dinâmica criada para os Laboratórios de Leitura, Gallian (2017, p. 8687) defende a importância de compartilhar as experiências de leitura entre os participantes: “o grande poder mobilizador da leitura do ponto de vista afetivo e reflexivo praticamente exige uma dinâmica de expressão e compartilhamento, concretizado numa situação de interlocução". Compartilhar seria uma necessidade humana e um "meio privilegiado de nos humanizarmos, de ampliar a esfera do nosso ser e de crescer em autoconhecimento" (GALLIAN, 2017, p. 106). Almeida Júnior e Bortolin (2008, p. 79) enfatizam que "a partilha do que foi lido com nossos mediandos" é fundamental e "esse compartilhamento acompanhado de uma cumplicidade

\footnotetext{
${ }^{4}$ Informações disponíveis em: 〈https://cehfi.unifesp.br/〉. Acesso em: 27 dez. 2020
} 
(mesmo quando existem divergências na leitura) é a receita perfeita para a permanência ou aparecimento do gosto pela leitura".

Outro aspecto importante da literatura é o texto literário possui lacunas a serem preenchidas pelo leitor. Segundo a terminologia da Estética da Recepção, o leitor "concretiza" a obra literária, "uma vez que sem sua participação ativa ela não poderia existir, em função das indeterminações que o texto literário apresenta, implicando processos de significação que só se materializam na prática da leitura" (OBERG, 2007, p. 32). Como afirma Umberto Eco, "as obras literárias nos convidam à liberdade da interpretação, pois propõem um discurso com muitos planos de leitura e nos colocam diante das ambiguidades e da linguagem da vida" (ECO, 2003, p. 12).

Por muito tempo, entretanto, as aulas de literatura funcionaram (e talvez até hoje funcionem) mais como aulas sobre a literatura, ou seja, mais que ler os textos, os alunos estudavam escolas literárias e suas características, biografias dos autores, termos técnicos sem a devida funcionalidade, e isso, segundo alguns estudiosos, acaba afastando os alunos da leitura literária, vista mais como um dever a cumprir. Todorov (2009), por exemplo, em A literatura em perigo, afirma que o ensino de literatura, sem relações com a carnalidade do mundo, não tem surpresas: "os alunos do Ensino Médio aprendem o dogma segundo o qual a literatura não tem relação com o restante do mundo, estudando apenas as relações dos elementos da obra entre si” (TODOROV, 2009, p. 39).

Petit (2017, p. 63) também fala da relação que geralmente ocorria com a literatura na escola:

\begin{abstract}
Na escola, por um longo período, estudou-se literatura como algo exterior, que não é vivido, constatado, sentido. Algumas abordagens são até mesmo voltadas para aprofundar a distância com o corpo, repudiar toda a emoção, vista como um desvario perigoso. E o corpo foi durante um bom tempo esquecido nas pesquisas sobre leitura, reduzida a uma atividade mental enquanto o que se dá é uma atividade física, engajando de maneira indissolúvel corpo e mente (PETIT, 2017, p. 63-64).
\end{abstract}

A valorização das reações subjetivas seria importante, segundo Yunes (2019), porque estas podem ser vistas como indícios de apropriação dos textos, catalisadoras de um trajeto interpretativo. Por isso, o ideal seria acolher e encorajar tais leituras subjetivas, uma vez que

\title{
a significação de um texto ficcional não se esgota na interpretação autorizada por uma instância reconhecida, ou por uma metodologia legitimada, passa a ter interesse o leitor que aporta a diferença em relação ao padrão de leitura consagrado por diluidores oficiais dos grandes críticos (YUNES, 2019, p. 37).
}

Cabe lembrar que a liberdade interpretativa do leitor está relacionada, mesmo inconscientemente, às comunidades interpretativas das quais participa (YUNES, 2019, p. 39) e como afirma Jouve, "o que retemos de texto depende prioritariamente de nossos centros de 
interesse" (2013, p. 58). Como exemplo podemos citar uma experiência pessoal: uma criança de 3 ou 4 anos insistia em ouvir novamente a "história do sapo". 5 Depois de uma conversa, descobriu-se que a criança se referia a uma contação de histórias em que a bibliotecária, vestida como Emília (personagem do Sítio do Pica Pau Amarelo), mostrou um sapo que havia engolido “pílulas falantes”. Interessante notar que a participação do sapo na história foi mais significativa para aquela criança do que todos os outros personagens, provavelmente porque o sapo fazia parte do seu repertório.

Esse repertório pode ser ampliado com novas leituras. Segundo Jauss, a literatura pode ter um papel transformador do leitor, propiciando a ampliação ou modificação de sua visão de mundo. Sua função social "se manifesta na plenitude de suas possibilidades quando a experiência literária do leitor adentra o horizonte de expectativa de sua vida prática, préformando seu entendimento do mundo e, assim, retroagindo sobre seu comportamento social" (JAUSS, 1994, p. 50).

A leitura serve para conhecer o mundo e a si mesmo e dessa possibilidade de autoconhecimento surgem projetos que usam a leitura literária com proposta terapêutica como a Biblioterapia. Segundo Sousa (2019, p. 109), a Biblioterapia, "cuidado com o desenvolvimento do ser humano por meio das histórias, sejam elas lidas, narradas ou dramatizadas", vem ganhando espaço no Brasil nos últimos anos, com destaque para o protagonismo de bibliotecários nessa área de atuação e de pesquisa.

A Biblioterapia é também usada por psicólogos em atendimentos individuais ou em grupos. Cristiana Seixas, em seu livro Vivências em Biblioterapia, relata como começou a usar os textos literários em seus atendimentos. A psicóloga medeia Círculos de Biblioterapia, "rodas de leitura com fins terapêuticos" (SEIXAS, 2014, p. 23), em que o mais importante é o que a leitura evoca e não o que o autor quis dizer, em outras palavras, não há interpretações incorretas. Em seu consultório, Seixas percebe "que em determinadas circunstâncias, um autor é capaz de descrever, melhor do que a própria pessoa, os sentimentos envolvidos em seu drama pessoal" (2014, p. 43).

Petit (2017) trata do poder da leitura em contextos de crise intensa

Em tais contextos, crianças, adolescentes e adultos poderiam redescobrir o papel dessa atividade na reconstrução de si mesmos e, além disso, a contribuição única da literatura e da arte para a atividade psíquica (PETIT, 2017, p. 22).

\footnotetext{
${ }^{5}$ Experiência vivenciada em 2019, na Biblioteca do CEU Azul da Cor do Mar, na qual trabalhei como Analista de Informações, Cultura e Desporto - Biblioteconomia, entre julho de 2016 e novembro de 2020
} 
A autora argumenta que seu papel é mais vasto que o terapêutico, "algo da ordem cultural, educativa e, por certos aspectos, política" (PETIT, 2017, p. 28); defende que o gosto pela leitura e sua prática são, na maioria das vezes, socialmente construídos e ressalta a importância das mediações nesses contextos de crise:

Se chegaram a ler, foi sempre graças a mediações específicas, ao acompanhamento afetuoso e discreto de um mediador com gosto pelos livros, que fez com que a apropriação deles fosse almejada (PETIT, 2017, p. 22).

Segundo Oberg (2007, p. 35), a inserção dos sujeitos em uma rede cada vez mais complexa de informações problematiza a noção de comunidade de leitores e também a construção de sentidos da leitura. Às formas tradicionais somam-se formas de acesso à informação e de comunicação à distância, possibilitando "a criação de comunidades e de espaços de pertencimento simultâneos, muito variados e distantes em termos de espaço real" (OBERG, 2007, p. 35). Dessa forma, multiplicam-se as mediações em termos numéricos e diversificam-se suas origens.

Há booktubers lançando suas análises sobre livros, telenovelas ${ }^{6}$, com enfoque voltado para a temática literária, com lançamento de podcasts, por exemplo. Na periferia crescem atividades como Slams $^{7}$ em praças, Saraus $^{8}$ em bares e leituras literárias em parques ${ }^{9}$, mostrando que, longe de estar falida, a musa ${ }^{10}$ ganha espaços na sociedade que não se restringem à escola ou às bibliotecas, tampouco é exclusividade de uma elite cultural.

A literatura, como exercício de invenção de novas realidades, não é somente um gesto da vida privada, mas se desenvolve nos espaços públicos através de movimentos poético-sociais, saraus, encontros, recitais, festivais e mostras que se realizam por

\footnotetext{
${ }^{6}$ Referimo-nos à telenovela Bom Sucesso, produzida e exibida pela Rede Globo de julho de 2019 a janeiro de 2020, segundo o site da emissora, disponível em: <https://gshow.globo.com/novelas/bom-sucesso/>. Acesso em:10 abr. 2020.

${ }^{7}$ Como exemplo, citamos o Slam da Guilhermina: "O Slam da Guilhermina é um campeonato de poesias faladas - o $2^{\circ}$ Poetry Slam do Brasil - evento que reúne mensalmente mais de trezentas pessoas em uma praça - arena - a céu aberto na Vila Guilhermina - Zona Leste Paulistana, desde fevereiro de 2012" Disponível em: https://www.facebook.com/slamdaguilhermina/>. Acesso em: 15 abr. 2020.

${ }^{8}$ Como exemplo citamos o Sarau do Binho: "Robinson Padial - mais conhecido como Binho - promove atividades culturais desde a década de 1990. Inicialmente, as pessoas reuniam-se para ouvir música e declamar poesia em seu bar. O sarau ganhou uma nova sede em 2012, o Espaço Clariô de Teatro, em Taboão da Serra (SP), e tem ampliado cada dia mais sua programação, buscando dar vazão à produção cultural da periferia da região metropolitana de São Paulo”. Disponível em: <https://www.itaucultural.org.br/sarau-do-binho>. Acesso em: 15 abr. 2020.

${ }^{9}$ Podemos mencionar o Projeto Piracaia na Leitura: "Projeto comunitário de incentivo e apoio à leitura que mantém 12 minibibliotecas livres em pontos de ônibus da cidade de Piracaia - SP, organiza saraus mensais no parque público e um festival literário anual”. Informações disponíveis em: <https://galpaobuscavida.com.br/piracaianaleitura/>. Acesso em: 15 abr. 2020.

${ }^{10}$ Fazemos alusão aqui ao texto: PÉCORA, Alcir; A Musa Falida. A perda da centralidade da literatura na cultura globalizada. Biblos (Coimbra), v. 1, 2015, p. 203-235, Coimbra, Portugal, 2015.
} 
todo o Brasil. Isso indica que a energia do fazer literário se nutre das relações e das ações culturais mais gerais.

A literatura em suas diversas formas - tradição oral, narrativa, poesia, crônica, conto - se constitui num modo de experiência cultural que dinamiza a vida social moderna e propicia trocas de experiências tanto de escritores como de leitores (SOUZA, 2008, p. 137-138).

São múltiplas, portanto, as possibilidades da literatura e por isso, segundo Rouxel (2013, p. 164) "afigura-se urgente reensinar os alunos a utilizar o texto para si mesmos, para sonhar, para reencontrar o gosto pela leitura". O trabalho de mediação da leitura literária em bibliotecas públicas poderia contribuir para esses encontros, contribuindo para que estas não fossem apenas locais para guarda e distribuição de livros, mas espaços de produção, recepção e compartilhamento de signos, ideias e experiências culturais múltiplas e diversificadas.

\section{Compartilhamento e escuta na mediação da leitura literária em bibliotecas}

A literatura, como visto no item anterior, tem um potencial relacionado à humanização, ao conhecimento, ao autoconhecimento, à formação cultural, a processos terapêuticos, entre outros, e o desafio para o mediador de leitura literária é criar oportunidades para que os leitores se expressem, acolhendo suas falas, ainda que essas se distanciem dos textos lidos. As mediações, além de tempo que vá na contramão da velocidade a nós imposta pela cultura contemporânea, necessitam de planejamento e conhecimentos específicos, disponibilidade e escuta atenta, segundo Petit (2017) e Bajour (2012). Dessa forma, a presença das bibliotecas poderia se tornar "um fator de proteção psíquico-social-linguístico, que trabalha no campo imaginário, que nutre de linguagem e de experiências de ordem simbólica as vidas contemporâneas" (LÓPEZ, 2019, p. 51). O desafio, para as bibliotecas públicas, de acordo com López (2019), não é somente configurar um cânone de leituras, mas também

projetar e oferecer o espaço-tempo simbólico necessário para que haja conexão com a linguagem, com a dialogia, a possibilidade de entrar no espaço poéticoliterário proporcionado por um romance, um conto, um poema. Aqui a interação e a conversação se tornam fundamentais (LÓPEZ, 2019, p. 51, grifos nossos).

A mediação cultural, entendida como paradigma, pode, nesse sentido, contribuir para que sejam criados leitores autônomos e conscientes de suas escolhas. O bibliotecário é, então, um mediador que acompanha essa trajetória, ajudando o leitor a ultrapassar umbrais, por exemplo, da seção infantil para a juvenil e desta para a adulta, como salienta PETIT (2013). Esse mediador "pode ser definido como uma pessoa que tem a responsabilidade de acompanhar um leitor durante a sua formação ou mesmo depois de formado", sendo a mediação de leitura "uma ação de interferência" (ALMEIDA JÚNIOR; BORTOLIN, 2008, p. 77). Tal ação pode 
participar na aproximação entre leitor e textos e entre leitores para além do intuito de alfabetização ou de aquisição de conhecimentos "úteis""11, ou seja, como possibilidade de converter leitura em experiência simbólica significativa, ato de produção e partilhamento de sentidos. Uma escuta atenta não se aprende instantaneamente, demanda tempo e compromisso, precisa ser alimentada por práticas e, como defende Bajour (2012, p. 40), por teorias, para reconhecer, apreciar e potencializar as falas dos leitores; ela implica vinculação, o desenvolvimento de "competências para acolher, ouvir e dialogar com o outro, implica a capacidade de escuta e observação sensíveis dos comportamentos que se desdobram da ação mediadora" (GOMES, 2014, p. 53).

Patte (2012, p. 67) em seu estudo também trata da importância fundamental da mediação, como ato de vinculação, de abertura, de aceitação do outro e sua singularidade: "uma mediação que respeite cada um na sua individualidade; que enfatize o literário em sua relação com a vida". Os bibliotecários-mediadores são vistos como barqueiros e testemunhas:

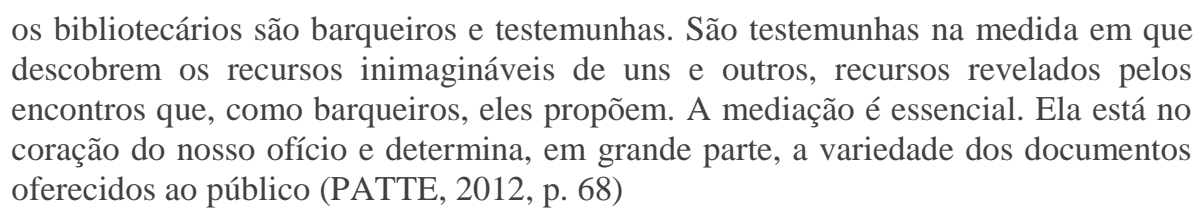

Na Apresentação ao livro Deixem que leiam, Daniel Goldin (2012) afirma que se arrisca a resumir em poucas linhas os princípios fundamentais em que se sustentaria o trabalho de uma biblioteca cujo objetivo é ser potencializadora da vida intelectual, afetiva e social de uma comunidade:

Em primeiro lugar, o respeito ao leitor, sua intimidade, seus desejos, conhecimentos e perguntas. Em segundo, o profundo conhecimento das obras e do acervo disponível, que não precisa ser muito extenso, conquanto seja bem selecionado e frequentemente revisado (GOLDIN, 2012, p. 7-8).

Com relação à mediação em bibliotecas públicas, Patte (2012) afirma que a leitura não pode prescindir da intimidade e da confiança. A autora insiste no refrão Small is beautiful, porque "a leitura não é assunto de massas e multidão, porque ela é mais bem vivida na intimidade e na confiança da relação em pequenos grupos informais ou face a face" (PATTE, 2012, p. 47). Dessa forma, se pensarmos de acordo com Patte (2012), a biblioteca necessitaria privilegiar os pequenos grupos informais e dispor de tempo para se entreter e se emocionar com a leitura. A biblioteca seria um lugar, como defende Petit (2017, p. 83), governado por um tempo particular, "feito de uma lentidão propícia ao devaneio, mas às vezes também de um

\footnotetext{
${ }^{11}$ Conhecimento útil, segundo Russell (2002, p. 38) é aquele que se pode aplicar a algum setor da vida econômica da coletividade.
} 
ritmo mais próximo do sensorial; e fala-se uma língua diferente da usada para a designação imediata e utilitária das coisas: a língua da narrativa".

Objetos culturais como os livros são signos, discursos e, ao mesmo tempo, são realidades concretas e objetivas. É preciso ter acesso material ao objeto, mas são essenciais saberes específicos para sua apropriação simbólica.

Quando se trata de mediação de leitura com crianças, por exemplo, segundo Patte (2012, p. 12), há a necessidade da presença interessada e discreta do adulto. Políticas centralizadas apenas em modelos distributivistas e transmissivistas, como as dos paradigmas de bibliotecas apresentados anteriormente, sem as mediações adequadas, têm se mostrado ineficientes.

\begin{abstract}
Modelos distributivistas e transmissivistas de educação, centralizados no acesso à cultura escrita e literária, incidem no equívoco da estetização do livro, que se traduz em posturas que colocam no objeto estético todo o poder de provocar o desejo de ler e desencadear a fruição literária realizando, por si só, o trabalho de formar o leitor. Esta convicção acaba por instituir práticas nas quais se ignora ou minimiza a importância das mediações socioculturais, apostando-se na naturalização do desejo e da fruição, como se os vínculos entre os sujeitos e os livros surgissem espontaneamente, constituindo-se apenas no contato com as obras, unicamente em função de suas qualidades estéticas (OBERG, 2007, p. 14-15).
\end{abstract}

A linguagem estética convida o leitor à fruição e à liberdade. A sociedade contemporânea, entretanto, muitas vezes não distingue os diferentes modos de recepção e de mediação, tratando os vários tipos de informação de forma padronizada. Em decorrência, Oberg (2007, p. 185), conclui que é preciso "reconhecer as diferenças existentes nos atos de significação, bem como as suas singularidades, compreendendo-se que diferentes informações pedem diferentes recepções e mediações e vice-versa, em todos os sentidos". A autora observa que a funcionalização da recepção dos textos literários, tanto nas bibliotecas quanto nos circuitos educacionais, aponta para a necessidade de reformulação de práticas e de mediação, de forma a fazer conviver "o intelectual e o sensível, a formalização e a informalidade dos saberes" (OBERG, 2007, p. 186). Em outro trecho, a autora fala do convite "sedutor" que deve ser feito ao leitor:

\footnotetext{
Nesta perspectiva, não basta que o texto literário seja belo, mas também as mediações precisam ser belas. Assim, as ações para a criação de condições de leitura e fruição literária precisam ser ajustadas não só às particularidades dos sujeitos, mas também ao objeto mediado. Se as imposições raramente dão bons resultados neste campo, é preciso reconhecer que também não se responde a qualquer convite. O convite a ser feito para a leitura é "sedutor", é “provocadoramente amável”, revelando o caráter erotizado das relações entre o leitor e o texto literário, como quer Barthes (OBERG, 2007, p. 146-147).
}

Por se tratar de uma categoria não apenas teórica, mas de prática complexa, especialmente "face às dificuldades próprias da cultura no mundo contemporâneo" (FARIA, 
1999, p. 186), a formação de mediadores de leitura implica diferentes competências, dentre elas, evidentemente, a sua formação enquanto sujeitos leitores (RASTELLI; CAVALCANTE, 2014, p. 52).

Por fim, cabe lembrar Gallian (2017) e Petit (2017), ao se referirem à importância da escolha das obras para mediação. Segundo eles, para despertar o interesse do interlocutor, o texto deve ter tocado primeiramente o próprio mediador. Como pontua Gallian (2017, p. 96), "ter experimentado o poder mobilizador da literatura [...] e estar convicto dele é o primeiro passo no caminho de convencer, estimular e envolver a outros nessa aventura". No mesmo sentido, ressalta Petit (2017, p. 22), “a leitura é uma arte que se transmite, mais do que se ensina".

Nesse sentido, na mediação da leitura literária, a escuta inicia-se já na seleção dos textos, quando escolhidos pelo mediador, na sua diversificação, na atenção à profundidade e ao desafio para a compreensão (PATTE, 2012; BAJOUR, 2012). Se ler é ato e gesto, ao oferecer um livro a um leitor, oferecemos um "quadro de valores, de representações, de conteúdos culturais que historicamente se agregaram ao objeto livro" (PIERUCCINI, 2004, p. 30).

\section{Considerações finais}

Numa época de ampla hegemonia das novas Tecnologias de Informação e Comunicação (TIC), pensar o lugar da biblioteca e da literatura apresenta-se como um desafio para os pesquisadores e profissionais da área, assim como refletir sobre as particularidades da mediação da leitura literária, distintas de práticas utilitaristas, que tenham a literatura valorizada em todo o seu potencial, para além do dever e da vida escolar.

Apesar das exigências próprias da chamada Era da Informação e de suas recorrentes cobranças de eficácia, eficiência, produtividade, parece difícil - e temeroso - fugirmos da observação feita por Antonio Candido (2004): o ser humano necessita de ficção e fantasia. Nesse sentido, a experiência literária é uma das possibilidades de satisfazer essa necessidade e as bibliotecas públicas, como possuem entre suas funções a promoção da leitura para todos os públicos, são locais potenciais para a leitura literária e também para a troca de saberes aí implicados.

Como espaços teoricamente privilegiados para a mediação cultural, as bibliotecas podem possibilitar relações vivas e dinâmicas aos sujeitos, não só com o conhecimento registrado, mas também com o conhecimento gerado através das relações interpessoais, 
permitindo-lhes aprendizagens especiais e específicas para lidar com as leituras e informações e apropriar-se delas.

O paradigma cultural adotado nas bibliotecas pode favorecer ou não a relação dinâmica e significativa da leitura literária. Não será a mesma experiência a relação com as obras em bibliotecas cujo paradigma seja de conservação, difusão ou mediação cultural.

Buscamos mostrar que as práticas de mediação de leitura literária precisam ser planejadas de forma criteriosa, à luz de conhecimentos específicos porque não se constituem em simples transmissão ou mera permissão de acesso aos bens culturais, impõem a necessidade de criar vínculos simbólicos, que valorizam a literatura como direito humano e propulsora de experiências e conhecimentos.

\section{Referências}

ALMEIDA JR., O. F.; BORTOLIN, Sueli. Mediação da informação e da leitura. In: SILVA, T. E. da. (Org.) Interdisciplinaridade e transversalidade em Ciência da Informação. Recife: Néctar, 2008.

BAJOUR, C. Ouvir nas entrelinhas: o valor da escuta nas práticas de leitura. São Paulo: Pulo do Gato, 2012.

BENJAMIN, W. Experiência e pobreza. In: BENJAMIN, W. Magia e técnica, arte e política. São Paulo: Brasiliense, 1993. p. 114-119.

BOSI, A. Considerações sobre tempo e informação. In: SEMINÁRIO "INTERNET, MENTE E SOCIEDADE", I, 1995, São Paulo. Anais... São Paulo: Instituto de Estudos Avançados da Universidade de São Paulo. Disponível em: <http://www.iea.usp.br/publicacoes/textos/bosiinternet.pdf/at_download/file>. Acesso em: 01 mai. 2020.

CANDIDO, A. A literatura e a formação do homem. Remate de Males, Campinas: SP, p. 8190, dez. 2012. Disponível em: <https://periodicos.sbu.unicamp.br/ojs/ index.php/remate/article/view/8635992/3701>. Acesso em: 16 jul. 2019.

CANDIDO, A. O direito à literatura. In: CANDIDO, A. Vários escritos. 5.ed. Rio de Janeiro: Ouro sobre Azul, 2004. p. 169-191.

CHARTIER, R. A aventura do livro: do leitor ao navegador: conversações com Jean Lebrun. São Paulo: Imprensa Oficial do Estado de São Paulo/Ed. Unesp, 2009.

COMPAGNON, A. Literatura para quê?? Belo Horizonte: Ed. UFMG, 2009.

ECO, U. Sobre algumas funções da literatura. In: ECO, U. Sobre literatura: ensaios. Rio de Janeiro: Record, 2003.

GALLIAN, D. A literatura como remédio: os clássicos e a saúde da alma. São Paulo: Martin Claret, 2017.

GOLDIN, D. Apresentação. In: PATTE, G. Deixem que leiam. Rio de Janeiro: Rocco, 2012. 
GOMES, H. F. A dimensão dialógica, estética, formativa e ética da mediação da informação. Informação \& Informação. Londrina, v. 19, n. 2, p. 46-59, mai/ago. 2014. Disponível em: <http://www.uel.br/revistas/uel/index.php/informacao/article/view/19994>. Acesso em: 07 abr. 2020 .

JAUSS, H. R. A história da literatura como provocação à teoria literária. São Paulo: Ática, 1994.

JOUVE, V. A leitura como retorno a si: sobre o interesse pedagógico das leituras subjetivas. In: ROUXEL, A.; LANGLADE, G.; REZENDE, N. L. (Org.). Leitura subjetiva e ensino de literatura. São Paulo: Alameda, 2013.

LANGLADE, G. O sujeito leitor, autor da singularidade da obra. In: ROUXEL, A.; LANGLADE, G.; REZENDE, N. L. (Org.). Leitura subjetiva e ensino de literatura. São Paulo: Alameda, 2013.

LARROSA, J. Experiência e alteridade em educação. Reflexão e Ação, Santa Cruz do Sul, v. 19, n. 2, p. 04-27, dez. 2011. Disponível em: <https://online.unisc.br/seer/index.php/ reflex/article/view/2444>. Acesso em: 16 jul. 2019.

LÓPEZ, M. E. Mediação e formação de leitores. In: Mediação: cultura, leitura e território. São Paulo: Secretaria de Cultura e Economia Criativa do Estado de São Paulo, Unidade de Difusão Cultural, Bibliotecas e Leitura, SP Leituras, 2019. Notas de biblioteca, v. 12, p. 47-62.

OBERG, M. S. P. Informação e significação: a fruição literária em questão. 2007. Tese (Doutorado em Cultura e Informação) - Escola de Comunicações e Artes, Universidade de São Paulo, São Paulo, 2007. Disponível em: <https://www.teses.usp.br/teses/disponiveis /27/27151/tde-23072009-161746/publico/1368444.pdf>. Acesso em: 11 abr 2020.

OLIVEIRA, A. L. de. Cultura na fazenda: um estudo sobre a apropriação da leitura como negociação de sentidos. 2009. Dissertação (Mestrado em Cultura e Informação) - Escola de Comunicações e Artes, Universidade de São Paulo, São Paulo, 2009. Disponível em: <https://www.teses.usp.br/teses/disponiveis/27/27151/tde-19102009-142344/pt-br.php>. Acesso em: 04 abr. 2020.

PATTE, G. Deixem que leiam. Rio de Janeiro: Rocco, 2012.

PAULINO, G. Círculo de leitura. In: FRADE, Isabel Cristina Alves da Silva; VAL, Maria da Graça Costa; BREGUNCI, Maria das Graças de Castro. (Orgs.). Glossário Ceale: termos de alfabetização, leitura e escrita para educadores. Belo Horizonte: Faculdade de Educação da UFMG, 2014. Disponível em: http://ceale.fae.ufmg.br/app/webroot/glossarioceale /verbetes/leitura-literaria. Acesso em: 27 fev. 2020.

PERROTTI, E. Infoeduação: um passo além científico-profissional. Informação@Profissões. Londrina, v. 5, n. 2, p. 04-31, jul./dez. 2016. Disponível em: <http://www.uel.br/revistas/uel/index.php/infoprof/article/view/28314>. Acesso em: 26 fev. 2020.

PERROTTI, E. Sobre informação e protagonismo cultural. In: GOMES, H.F; NOVO, H.F. (org.). Informação e protagonismo social. Salvador: EDUFBA, 2017, p.8-26.

PERROTTI, E; PIERUCCINI, I. A mediação cultural como categoria autônoma. Informação \& Informação, [S.1.], v. 19, n. 2, p. 01-22, out. 2014. Disponível em: <http://www.uel.br/revistas/uel/index.php/informacao/article/view/19992>. Acesso em: 15 nov. 2017. 
PERROTTI, E; PIERUCCINI, I. Infoeducação: saberes e fazeres da contemporaneidade. In: LARA, M. L. G.; FUJINO, A.; NORONHA, D. P. (Org.). Informação e contemporaneidade: perspectivas. Recife: Néctar, 2007, p. 46-95. <http://www2.eca.usp.br/nucleos/ colabori/documentos/Infoeducacao.pdf>. Acesso em: 15 nov. 2017.

PETIT, M. A arte de ler ou como resistir à adversidade. São Paulo: Ed. 34, 2017.

PETIT, M. Os jovens e a leitura: uma nova perspectiva. São Paulo: Editora 34, 2013.

PIERUCCINI, I. Ordem informacional dialógica: mediação como apropriação da informação. In: ENANCIB - ENCONTRO NACIONAL DE PESQUISA EM CIÊNCIA DA INFORMAÇÃO, 8., 2007, Salvador. Anais eletrônicos... Salvador, 2007. Disponível em: <http://www.enancib.ppgci.ufba.br/artigos/GT3--159.pdf>. Acesso em: 26 fev. 2020.

PIERUCCINI, I. A ordem informacional dialógica: estudo sobre a busca de informação em Educação. 2004. 232 f. Tese (Doutorado em Ciência da Informação) - Escola de Comunicações e Artes. Universidade de São Paulo, São Paulo, 2004.

RASTELLI, A.; CAVALCANTE, L. E. Mediação cultural e apropriação da informação em bibliotecas públicas. Encontros Bibli: revista eletrônica de biblioteconomia e ciência da informação, v. 19, n. 39, p. 42-58, jan/abr. 2014. Disponível em: <https://periodicos.ufsc.br/index.php/eb/article/view/1518-2924.2014v19n39p43/26577>.

Acesso em: 11 abr. 2020.

ROUXEL, A. A tensão entre utilizar e interpretar na recepção das obras literárias em sala de aula: reflexão sobre uma inversão de valores ao longo da escolaridade. In: ROUXEL, A.; LANGLADE, G.; REZENDE, N. L. (Org.). Leitura subjetiva e ensino de literatura. São Paulo: Alameda, 2013.

RUSSELL, B. O conhecimento inútil. In: O elogio ao ócio. Rio de Janeiro: Sextante, 2002. p. 36-46.

SANTOS, M. A. de C. dos. Do igual, o igual, conversas desarmadas: um estudo sobre a experiência estética da leitura dialógica em Clubes de Leitura. São Paulo, 2019. 71 f. Dissertação (Mestrado em Psicologia Social). Instituto de Psicologia, Universidade de São Paulo, São Paulo, 2019. Disponível em: <https://www.teses.usp.br /teses/disponiveis/47/47134/tde-27062019-103207/pt-br.php>. Acesso em: 07 abr. 2020.

SEIXAS, C. Vivências em Biblioterapia: práticas do cuidado através da literatura. Niterói: Ed. do Autor, 2014.

SOUSA, C. Biblioterapia e a mediação afetuosa da literatura: experiências de bibliotecári@s em bibliotecas. In: PRADO, J. (Org). Mediação da leitura literária em bibliotecas. Rio de Janeiro: Malê, 2019.

SOUZA, V. de. Cultura e literatura: diálogos. São Paulo: Ed. do Autor, 2008. Disponível em: <https://www.polis.org.br/uploads/1524/1524.pdf>. Acesso em 17 abr. 2020.

TODOROV, T. A literatura em perigo. Rio de Janeiro: DIFEL, 2009.

YUNES, E. A leitura e a literatura como direitos e princípios de cidadania. In: Mediação: cultura, leitura e território. São Paulo: Secretaria de Cultura e Economia Criativa do Estado de São Paulo, Unidade de Difusão Cultural, Bibliotecas e Leitura, SP Leituras, 2019. Notas de biblioteca, v. 12, p. 33-46. 